\title{
Pluralismo bajo control: evolución de la Ley de partidos políticos en Argelia
}

\author{
Pluralism under Control: Evolution \\ of the Law of Political Parties in Algeria
}

\section{CARMELO PÉREZ BELTRÁN*}

Resumen: Se analiza la evolución de la ley sobre la creación y el funcionamiento de los partidos políticos en Argelia, desde la independencia del país en 1962 hasta la actualidad. Se distinguen tres etapas que dieron lugar, respectivamente, a la Ley de 1989 relativa a las asociaciones de carácter político, la Ley orgánica de 1997 relativa a los partidos políticos y la Ley Orgánica de 2012 referente a los partidos políticos. Se parte de una doble hipótesis: que la ley ha seguido una tendencia represiva y que es un instrumento legal al servicio de las estrategias políticas y sociales del régimen establecido con el fin de limitar el campo de acción de la oposición política.

Palabras clave: Ley de partidos políticos; Argelia; cambios jurídicos.

Abstract: This article studies the evolution of Algerian law on the creation and functioning of political parties from the country's independence in 1962 up to the present time. We can distinguish between three periods that gave birth to the 1989 Law of Political Associations, the 1997 Organic Law of Political Parties, and the current 2012 Organic Law of Political Parties. This study takes as its point of departure a double hypothesis: that the law of political parties has followed an increasing repressive trend, and that it is a legal instrument serving the political and social strategies of the

Recepción: 14 de enero de 2016. / Aceptación: 28 de marzo de 2016.

*Universidad de Granada, carmelop@ugr.es 
establishment in order to limit the field of action of the political opposition.

Key words: Law of political parties; Algeria; legal changes.

\section{Introducción}

Este artículo tiene por objetivo estudiar la evolución de la legislación sobre la creación y el funcionamiento de los partidos políticos en Argelia desde la independencia del país en 1962 hasta la actualidad. Se distinguen tres etapas: la primera, relacionada con el proceso de liberalización política de la década de 1980, dio lugar a la Ley de 1989 relativa a las asociaciones de carácter político; la segunda, enmarcada en la espiral de violencia que azotó al país en los años noventa, propició la Ley orgánica de 1997 relativa a los partidos políticos; y, finalmente, las recientes revueltas durante la Primavera Árabe estimularon la adopción de la Ley Orgánica de 2012 referente a los partidos políticos, sobre la que me centraré de manera especial por ser la normativa vigente en la actualidad.

Este trabajo parte de una doble hipótesis. En primer lugar, que la ley de partidos políticos ha seguido una tendencia represiva que se mantiene, e incluso se acentúa, en la reciente legislación de 2012. En segundo lugar, que a pesar de los diferentes contextos en los que se enmarcan las tres etapas señaladas, la ley de partidos es un instrumento legal al servicio de las estrategias políticas y sociales del régimen establecido, personificado en la figura del ministro del Interior, a fin de limitar el campo de acción de la oposición política.

\section{Del partido único al multipartidismo: la Ley de 1989 relativa a las asociaciones de carácter político}

Hablar de una legislación que regule la creación y el funcionamiento de los partidos políticos presupone un sistema pluripartidista, participativo y competitivo. ${ }^{1}$ Si trasladamos esta

${ }^{1}$ Véase Rafael Bustos, “Estudio sobre la poliarquía en Argelia: lógicas de partici- 
experiencia al caso concreto de Argelia, no podemos hablar de pluripartidismo hasta la adopción de la Constitución de 1989, que puso punto final a 27 años de un sistema presidencialista de partido único, dominado por el histórico Frente de Liberación Nacional (FLN), el cual, ya en la primera Constitución argelina de 1963, aprobada durante la presidencia de Ben Bella (1962-1965), aparecía como inspirador de la política y la acción del Estado (art. 24. ${ }^{\circ}$ ), el reflejo de las aspiraciones de las masas (art. 25. ${ }^{\circ}$ ) y el principio de unidad (art. 22. ${ }^{\circ}$ ) al que debe estar supeditado cualquier derecho o libertad. De hecho, en esa época se prohibieron las formaciones que pretendían mantener cierta tendencia autónoma o crítica, como fue el caso del Partido Comunista Argelino (PCA), prohibido en noviembre de 1962; el Partido de la Revolución Socialista (PRS), establecido por Mohammed Boudiaf en ese mismo año, o el Frente de Fuerzas Socialistas (FFS), fundado por Hocine Aït Ahmed en 1963, que pasaron a la clandestinidad.

El sistema unipartidista se consolidó bajo el régimen de Huari Bumedien (1965-1978), como quedó reflejado en la Carta Nacional y en la nueva Constitución de 1976, que establecían al FLN como "instrumento de Estado para guiar a la sociedad en estrecha y confusa integración con el ejército". ${ }^{2}$ Tal y como aparece en el título segundo de la Constitución de 1976, dedicado al poder y su organización, "el sistema institucional argelino reposa sobre el principio del partido único" (art. 94. ${ }^{\circ}$ ), y se especifica a continuación, por si quedaba alguna duda, que "el Frente de Liberación Nacional es el partido único del país" (art. 95. ${ }^{\circ}$ ). En resumen, la Constitución de 1976 establece una clara identificación entre el partido y el Estado, al tiempo que hace del FLN el eje central de la vida política e ideológica del país. En este sistema, las elecciones tenían tres funciones principales: ${ }^{3}$ refrendar al régimen y sus reglamentos orgánicos, confirmar o

pación y competición en las elecciones argelinas”, en I. Álvarez-Ossorio y L. Zaccara (eds.), Elecciones sin elección. Los procesos electorales en Oriente Medio y el Magreb, Madrid, Ediciones del Oriente y el Mediterráneo, 2009, pp. 326-347.

2 Juan Montabes, Las otras elecciones. Los procesos y sistemas electorales en el Magreb, Madrid, Agencia Española de Cooperación Internacional, 1999, p. 203.

${ }^{3}$ Rafael Bustos, "Elecciones y cambio político en Argelia", en María Angustias Parejo (ed.), Entre el autoritarismo y la democracia. Los procesos electorales en el Magreb, Barcelona, Bellaterra, 2010, p. 157. 
seleccionar a los candidatos propuestos por el propio partido y extender la presencia del partido al ámbito departamental o regional (wilayas) y comunal (dairas).

Si el acceso al poder de Chadli Bendjedid en 1979 ya puso de manifiesto fuertes tensiones entre los partidarios de la liberalización económica y los defensores de seguir profundizando en la vía socialista, la siguiente década estuvo marcada por una importante crisis del modelo rentista, basado en la explotación de los hidrocarburos que, hasta ese momento, había caracterizado la economía del país. Como respuesta a la crisis se puso en marcha un Plan de Ajuste Estructural (1986-1991), cuya consecuencia más importante fue el "desmantelamiento del sector público productivo y el paso de los hidrocarburos a manos de las multinacionales". ${ }^{4}$ La grave crisis económica, unida a las precarias condiciones de vida de la población y a esa política de recortes que descuida la cobertura de las necesidades básicas de los ciudadanos (salud, educación, vivienda y empleo), desembocaron en las trascendentales revueltas sociales de octubre de 1988, duramente reprimidas con la intervención del ejército, pero que, sin embargo, fueron el verdadero detonante del cambio político. De este modo, con el objetivo de calmar la espiral de violencia que azotaba los principales centros urbanos del país y que provocó unos 500 muertos, ${ }^{5}$ el presidente Bendjedid anunció reformas constitucionales que, aunque en un principio fueron más bien puntuales y simbólicas (reforma del 3 de noviembre de 1988), posteriormente lograron romper con el continuismo para imponer, a través de la Constitución del 23 de febrero de 1989, un nuevo sistema político ${ }^{6}$ que suprimía toda referencia al socialismo, establecía la separación de poderes, quitaba protagonismo político al FLN y al ejército y, por medio del artículo 40, reconocía el derecho a crear "asociaciones de

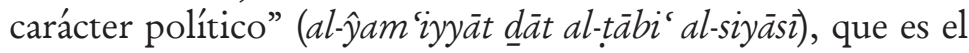

${ }^{4}$ Aurelia Mañé Estrada, “Ajuste estructural en Argelia. Un diagnóstico equivocado para una difícil reforma”, Nación Árabe, núm. 36, 1998, p. 116.

${ }^{5}$ Dirk Beke, "La Constitution algérienne de 1989 : une passerelle entre le socialiste et l'islamisme?”, Afrika Focus, año 7, núm. 3, 1991, p. 245.

${ }^{6}$ Véase Omar Bendourou, "La nouvelle Constitution algérienne du 28 février 1989”, Revue de Droit Publique, núm. 5, 1989, pp. 1305-1328; Gema Martín Muñoz, "La nueva Constitución argelina: hacia la III República", Revista de Estudios Políticos, núm. 67, 1990, pp. 261-296. 
término, algo eufemístico, con el que se viene a denominar a los partidos, lo cual deja entrever los graves conflictos internos y las resistencias al cambio democrático.

Como sostiene Tahar Khalfoun, ${ }^{7}$ en un principio hubo una doble interpretación de la expresión "asociación de carácter político”. Algunos consideraban que se debía circunscribir a las distintas tendencias o sensibilidades dentro del propio FLN y de sus organizaciones de masas; otros, por el contrario, aun reconociendo la ambigüedad del término, consideraban que debía entenderse como sinónimo de partido político. Por su parte, Dirk Beke señala que "este término fue empleado, según el presidente Chadli, de forma intencionada para permitir a los grupos políticos adherirse bien al FNL o a un nuevo 'frente político', sin prohibir por ello los partidos fuera del FLN”, y enseguida afirma que "otros términos como el de pluralismo político o multipartidismo tampoco están explícitamente utilizados en el texto constitucional, pero ahora están implícitamente legalizados". ${ }^{8}$

En cualquier caso, el devenir político demostró, sin ningún tipo de anfibología, que el artículo 40 citado instauraba un verdadero multipartidismo en Argelia, y se añadió a continuación que "este derecho no se podrá usar para atentar contra las libertades fundamentales, la unidad nacional, la integridad territorial, la independencia del país y la soberanía del pueblo”. Éste fue el marco constitucional en el que se promulgó la Ley 89-11 del 5 de julio de 1989 relativa a las asociaciones de carácter político, ${ }^{9}$ primera ley de partidos políticos de Argelia.

7 Tahar Khalfoun, "La loi sur les partis politiques : un pluralisme administré", en G. Meynier (ed.), L'Algérie contemporaine. Bilan et solutions pour sortir de la crise, París-Montreal, L'Harmattan, 2000, pp. 272-273.

${ }^{8}$ Beke, "La Constitution algérienne de 1989", op. cit., p. 253.

${ }^{9}$ El texto completo de esta ley puede consultarse en: República Argelina, "Q⿻̄nūn raqm 89-11 al-mu'arraj fī 2 dī l-hị̂ŷa 'ām 1409 al-muwāfiq 5 yūlīw sana 1989

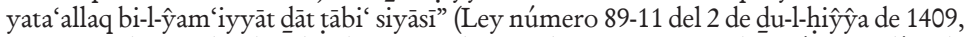
correspondiente al 5 de julio de 1989, relativa a las asociaciones de carácter político),

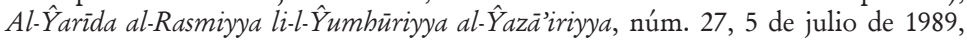
pp. 714-718. Versión francesa en: République Algérienne, "Loi no 89-11 du 5 juillet 1989 relative aux associations à caractère politique" (Ley núm. 89-11 del 5 de julio de 1989 relativa a las asociaciones de carácter político), Journal Officiel de la République Algérienne, núm. 27, 5 de julio de 1989, pp. 604-607. 
La Ley 89-11, estructurada en cinco títulos y 44 artículos, define la asociación de carácter político como un grupo de ciudadanos argelinos que "en torno a un programa político y con un fin no lucrativo trabaja para participar en la vida política por medios democráticos y pacíficos" (art. 2. ${ }^{\circ}$ ), y prohíbe la posibilidad de basar su creación o su acción en cuestiones confesionales, lingüísticas, regionales, raciales, profesionales o de género, así como en prácticas sectarias y feudales o en comportamientos contrarios a la moral islámica y a los valores de la Revolución de 1954 (art. 5. ${ }^{\circ}$ ). En la misma línea identitaria, la Ley de 1989 , en su artículo $4 .^{\circ}$, establece la "lengua nacional", ${ }^{10}$ es decir, el árabe, como única lengua del partido para cualquier asunto oficial; lengua que también debe ser utilizada en la principal publicación de la asociación política (art. 21. ${ }^{\circ}$ ), lo cual supone no pocos puntos de conflicto para las élites francófonas y para los movimientos culturales bereberes que, por esas mismas fechas, se encontraban en plena lucha por la defensa de su lengua, sus costumbres y su identidad en la denominada "Primavera Beréber". ${ }^{11}$

Inscribiéndose siempre en el respeto de la Constitución de 1989 (art. 6. $^{\circ}$ ), la Ley 89-11 dedica el título segundo (arts. 11. ${ }^{\circ}$ $\left.21 .^{\circ}\right)$ a la creación de los partidos, que "se efectúa mediante el depósito de un expediente ante el ministro del Interior a cambio de un recibo" (art. 11. ${ }^{\circ}$ ), es decir, mediante una declaración constitutiva. Dicho expediente debe contener tres ejemplares de los estatutos con los objetivos, la composición y el funcionamiento interno del partido (art. $13 .^{\circ}$ ), además de una solicitud firmada por tres miembros fundadores, los cuales deben aportar, también, sus certificados de nacimiento y nacionalidad y un extracto de sus antecedentes penales (art. 12. ${ }^{\circ}$ ). Dichos fundadores deben disfrutar de plenos derechos civiles, tener una edad mínima de 25 años y no sólo residir en territorio nacional, sino tener nacionalidad argelina de origen o con una antigüedad mínima de 10 años (art. 19. ${ }^{\circ}$ ). En cuanto al número

${ }^{10}$ Artículo 3. ${ }^{\circ}$ de la Constitución de 1989: "El árabe es la lengua nacional y oficial”. Martín Muñoz, "La nueva Constitución argelina”, op. cit., p. 266.

${ }^{11}$ Véanse, entre otros: Maxime Aït Kaki, De la question berbère au dilemme kabyle à l'aube du XXI siècle, París, L'Harmattan, 2004; Salem Chaker, "Quelques évidences sur la question berbère”, Confluences, núm. 11, 1994, pp. 105-114. 
de miembros exigidos para constituir un partido político, la ley menciona únicamente, en su artículo $14 .^{\circ}$, que "el número de fundadores y dirigentes no podrá ser inferior a quince (15)”, con lo cual la norma se muestra muy permisiva en este sentido.

Una vez depositado el expediente, el ministro del Interior dispone de dos meses para estudiar, valorar y verificar el contenido de la declaración, tras lo cual debe publicar los datos identificativos de la "asociación de carácter político" en el Boletín Oficial (arts. $15 .^{\circ}-16 .^{\circ}$ ), momento a partir del cual adquiere personalidad y capacidad jurídicas (art. 20. ${ }^{\circ}$ ). Desde el punto de vista económico (Título tercero), la Ley 89-11 señala la posibilidad de obtener recursos a través de cuatro medios (art. 22..$\left.^{\circ}\right)$ : las cuotas de los miembros, las donaciones y los legados, las ganancias derivadas de sus actividades y las posibles ayudas del Estado. No obstante, establece algunas limitaciones para controlar el poder económico de los partidos; entre ellas, una cuota máxima de 200 dinares argelinos (DA) mensuales (art. 23. ${ }^{\circ}$ ) y un máximo de $20000 \mathrm{DA}$ procedentes de donaciones y legados, siempre que éstos no representen más de $20 \%$ de los recursos procedentes de las cuotas de los miembros (art. 25. ${ }^{\circ}$ ). Igualmente, la ley prohíbe recibir cualquier tipo de apoyo económico o material procedente del extranjero (art. 26..$^{\circ}$ ), aunque el partido puede beneficiarse de ayudas del Estado, que siempre serán proporcionales al número de diputados en el Parlamento (art. 29. ${ }^{\circ}$ ). Finalmente, la norma obliga a los partidos a llevar a cabo una doble contabilidad y un inventario de sus bienes muebles e inmuebles, a presentar sus cuentas anuales a la administración, a justificar el origen y la utilización de sus recursos (art. 31. ${ }^{\circ}$ ) y a disponer de una cuenta corriente en un banco nacional (art. 32. ${ }^{\circ}$ ).

El Título cuarto de la Ley 89-11 está dedicado a las disposiciones penales. Quizá lo más significativo es la preponderancia del Ministerio del Interior, el cual puede obtener por vía judicial la suspensión de las actividades de la asociación y el cierre de sus locales si considera que está actuando en contra de la ley o en caso de urgencia o riesgo inminentes (art. 33. ${ }^{\circ}$ ). Igualmente, las penas para los dirigentes y los miembros de los partidos que infrinjan las disposiciones de la norma son bastante graves y conllevan penas de cárcel de entre uno y cinco años, y multas de 
3000 a $70000 \mathrm{DA}\left(\right.$ art. $36 .^{\circ}$ ), además de otras posibles sanciones estipuladas en el Código Penal (arts. $37 .^{\circ}-38 .^{\circ}$ ).

En resumen, la Ley 89-11 relativa a las asociaciones de carácter político se caracteriza, en primer lugar, por una amplia permisibilidad al crear un partido político, aunque intente controlar los recursos económicos y otorgue amplios poderes al Ministerio del Interior para suspenderlo en caso de necesidad. Igualmente, su articulado se caracteriza por una excesiva vaguedad e indefinición; de hecho, los 44 artículos que la componen son tan escuetos (apenas cuatro páginas del Boletín Oficial del Estado) que más bien se trata de líneas directrices sujetas a diversas interpretaciones. Teniendo en cuenta lo anterior, no es de extrañar que para las elecciones locales del 12 de junio de 1990 casi todas las solicitudes presentadas ante el Ministerio del Interior fueran aprobadas de manera casi automática ${ }^{12}$ y que lograran la legalización unos 60 partidos políticos, ${ }^{13}$ la mayoría de los cuales eran pequeños grupúsculos con escasa capacidad de movilización. ${ }^{14}$ No era el caso del Frente Islámico de Salvación (FIS), que obtuvo su legalización el 6 de septiembre de $1989,{ }^{15} \mathrm{y}$ que se convirtió en el principal "partido antisistema", ${ }^{16}$ dotado de una relevante capacidad de protesta política y movilización social. En buena medida, la legalización del FIS en 1989

12 Solamente fue rechazada la solicitud del Partido del Pueblo Argelino (PPA), con base en lo estipulado en el artículo $8 .^{\circ}$ de la Ley: "Ninguna asociación de carácter político podrá dotarse del mismo nombre, sede u otros signos distintivos que hayan pertenecido a una asociación preexistente o que hayan pertenecido a un movimiento cuya actitud o acción hayan sido contrarias a los intereses de la Revolución de liberación nacional". En este sentido, el PPA existió como tal de 1937 a 1939, creado por Messali Hadj, aunque detrás de esta prohibición también se pueden intuir las conflictivas relaciones históricas entre este carismático líder, que en 1954 fundó el Movimiento Nacional Argelino, y la dirección del FLN. Véase Beke, "La Constitution algérienne de 1989”, op. cit., nota 25, p. 271.

${ }^{13}$ Ahmed Aghrout, "Reformas políticas en Argelia. ¿Cambios verdaderos o meros ajustes?”, en Y. H. Zoubir y H. Amirah (coords.), El Magreb. Realidades nacionales y dinámicas regionales, Madrid, Síntesis, 2008, p. 64.

${ }^{14}$ Véase Moncef Djaziri, "La problématique partisane dans les systèmes politiques du Maghreb. Relance des études comparatives", Annuaire de l'Afrique du Nord, núm. 34, 1995, p. 427.

${ }^{15}$ Sobre la creación del FIS y sus estrategias, véase Laurance Thieux, Islamismo y democracia en Argelia. Francia y Estados Unidos frente al conflicto, Madrid, Ediciones del Oriente y del Mediterráneo, 2008, pp. 33-79.

${ }^{16}$ Véase Lahouari Addi, "Les partis politiques en Algérie”, Revue des Mondes Musulmans et de la Méditerranée, núm. 111-112, 2006, pp. 139-162. 
demuestra cierta lectura laxa de la Ley de partidos, así como la intencionalidad de dar cobertura a un amplio espectro ideológico del país, puesto que la administración podría, de igual forma, haber apelado a su artículo $5 .^{\circ}$ para prohibirlo, debido a su innegable base religiosa.

El FIS se convirtió en la única fuerza de oposición capaz de arrebatar el poder, por medios democráticos, a los gerifaltes del régimen argelino, que, desde la independencia del país en 1962, estaba estructurado en torno al ejército. ${ }^{17}$ Como afirma Rosa Meneses, el sistema multipartidista que introdujo la Constitución de 1989 era una simple fachada, porque "el régimen sólo acepta partidos que renuncien al poder; pueden hacer política, participar en las elecciones, pero deben renunciar a ganar. Cuando los partidos no aceptan este juego, el Estado actúa". ${ }^{18}$ Esto explica, en buena medida, la dinámica violenta en la que se vio sumido el país, ya que no todos los partidos acataron esta directriz, como ocurrió con el FIs, y ante ello el régimen actuó de modo contundente.

No es objetivo de este trabajo analizar el conflicto generado a partir de la liberalización política de 1989, aunque, grosso modo, podemos decir que

[...] las revolucionarias reformas introducidas a finales de los años ochenta serán suprimidas bruscamente con el golpe de Estado de 1992 que, protagonizado por el ejército y refrendado por ciertos sectores laicos de la sociedad civil que sirvieron de plataforma legitimadora, tenía por finalidad inmediata evitar una segura victoria del FIS en la segunda vuelta de las elecciones legislativas y, a más largo plazo, reubicar al ejército y a sus redes clientelares en los resortes del poder político y económico. El balance posterior es aterrador: más de 150000 muertos en una guerra sucia en donde el ejército y las fuerzas de seguridad del Estado han desempeñado un papel más que dudoso y cuyas consecuencias más violentas aún sigue sufriendo el país hoy en día. ${ }^{19}$

${ }^{17}$ Según Lahouari Addi, "los países del Tercer Mundo cuya independencia ha sido adquirida por la violencia presenta sistemas políticos estructurados en torno al ejército". Véase su artículo "L'armée, la nation et l'État en Algérie", Confluences Méditerranée, núm. 29, 1999, p. 39.

${ }^{18}$ Rosa Meneses, "La exclusión del islam político en Argelia. Implicaciones y consecuencias de la inacabada construcción del Estado", Afers Internacionals, núms. 9394, 2011, p. 80.

${ }^{19}$ Carmelo Pérez Beltrán, "Democracia, sociedad civil y derechos humanos en el Magreb”, Nova África, núm. 12, 2003, pp. 85-86. 


\section{Hacia la normalización política e institucional: la Ley orgánica de 1997 relativa a los partidos políticos}

Como sostiene Yahia Zoubir, tras la anulación de las elecciones legislativas, "el régimen argelino no contaba con ninguna estrategia con la que superar la crisis política sobrevenida. La debilidad del gobierno condujo a un agravamiento de la violencia que casi destruyó al Estado entre 1993 y 1995”. ${ }^{20}$ Aunque durante la década de los años noventa la población sufrió irremediablemente las nefastas consecuencias de la violencia, la situación política empezó a cambiar lentamente a partir de las elecciones presidenciales de noviembre de 1995, que no sólo sirvieron para legitimar en el poder a Liamine Zéroual, designado presidente por el Alto Comité de Estado en junio de 1994, sino también para restablecer la normalización política y la legalidad institucional del Estado.

A pesar de que Zéroual llevó a cabo distintas estrategias de negociación con los líderes islamistas para acabar con la violencia de grupos armados de muy diversa procedencia (estrategias todas que acabaron en fracaso), la política presidencial durante esta época se caracterizó por su alineamiento con los grupos denominados "erradicadores", es decir, los partidarios de la total exclusión y eliminación del fis del juego político. En este sentido, lo más significativo de aquel momento fue el rechazo categórico del gobierno a la denominada "Plataforma para una solución política y pacífica de la crisis argelina”, celebrada en enero de 1995 bajo el patrocinio de la comunidad religiosa de San Egidio (Roma), que reunió a los principales partidos políticos de oposición con el fin de establecer medidas que debían preceder a las negociaciones con el gobierno, como la liberación efectiva de los dirigentes del FIs y de todos los presos políticos, el repudio a la implicación del ejército en asuntos políticos, el respeto de las libertades democráticas y los derechos humanos, el rechazo de cualquier tipo de dictadura, el final inmediato de las prácticas de tortura, el cese de los atentados contra civiles y extranjeros, la vuelta a la legalidad constitucional y la soberanía popular, etcétera.

${ }^{20}$ Apud Aghrout, "Reformas políticas en Argelia", op. cit., p. 65. 
Como primera medida para reactivar la normalización política e institucional, Zéroual promovió una nueva reforma de la Constitución, sometida a referéndum el 28 de noviembre de 1996, que se caracteriza por dos cuestiones principales: reforzar los poderes presidenciales e incorporar una segunda cámara parlamentaria o Consejo de la Nación (Maŷlis al-Um$\mathrm{ma}$ ), cuyos miembros son elegidos mediante dos procedimientos diferentes: dos terceras partes por sufragio indirecto entre los miembros de las Asambleas Comunales y de las wilayas, mientras que el tercio restante es designado directamente por el propio presidente de la República (art. 101. ${ }^{\circ}$ ), lo que insiste de nuevo en esa ampliación de las prerrogativas presidenciales ya señaladas, que limitan los poderes del Parlamento. En la misma dirección apuntan los derechos que la reforma constitucional de 1996 otorga al presidente para legislar mediante decretos durante los periodos vacacionales de los parlamentarios, durante el periodo entre sesiones parlamentarias o en caso de estado de excepción (art. 124. ${ }^{\circ}$ ).

En cuanto al sistema político, la Constitución de 1996 ya habla sin ambages del multipartidismo como base del orden democrático (art. 178.2) y dedica un extenso artículo al derecho a crear partidos políticos, los cuales "no podrán estar fundados sobre una base religiosa, lingüística, racial, de sexo, corporativa o regional", ni podrán ser utilizados "para atentar contra las libertades fundamentales, los valores y componentes fundamentales de la identidad nacional, la unidad nacional, la seguridad, la integridad del territorio nacional, la independencia del país y la soberanía del pueblo, así como al carácter democrático y republicano del Estado"; tampoco podrán obedecer a intereses extranjeros o recurrir a la violencia en cualesquiera de sus formas $\left(\operatorname{art} .42 .^{\circ}\right)$. Éste fue el nuevo marco que amparó la Orden 97-09 del 6 de marzo de 1997 que contiene la Ley orgánica relativa a los partidos políticos, ${ }^{21}$ que, en líneas generales y como

${ }^{21}$ Texto completo de esta Ley Orgánica en: República Argelina, “Amr raqm 9709 mu’arraj fî 27 šawāl ‘ām 1417 al-muwāfiq 6 mārs sana 1997 yatadamman al-qānūn al-‘ự̂īi al-muta'allaq bi-l-aḥzāb al-siyāsiyya" (Orden número 97-09 del 27 de šawāl de 1417, correspondiente al 6 de marzo de 1997, que contiene la Ley orgánica relativa a

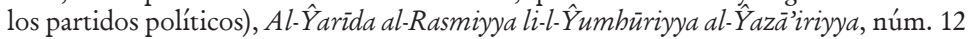
(27 šawāl de 1417), 6 de marzo de 1997, pp. 30-35. Versión francesa en: République Algérienne, “Ordonnace no 97-09 du 27 chaoual 1417 correspondant au 6 mars 1997 
veremos a continuación, se caracteriza por una "voluntad real de someter el pluralismo al control de la administración”. ${ }^{22}$

Lo más destacado de la Ley Orgánica de 1997 es el complicado procedimiento para constituir un partido político, que debe pasar por una "doble autorización previa", supeditada en ambas fases al control del Ministerio del Interior, que puede contar con hasta cuatro meses para valorar la pertinencia o no de legalizar un partido.

El primer paso para crear un partido político al amparo de la Ley Orgánica de 1997 consiste en el depósito ante el ministro del Interior de un expediente constitutivo (art. 12. ${ }^{\circ}$ ) que, entre otras cuestiones, debe incluir (art. 14. ${ }^{\circ}$ ): la solicitud de constitución, el compromiso de al menos 25 miembros fundadores, tres ejemplares de los estatutos provisionales y diversos documentos relacionados con la identificación y la situación legal de los fundadores. Dicho expediente se acredita mediante la entrega de un resguardo (art. $12 .^{\circ}$ ). Comienza entonces la primera fase de autorización administrativa, ya que el ministro del Interior dispone de 60 días para permitir o denegar, mediante una decisión razonada, la solicitud (art. $17 .^{\circ}$ ), aunque también es cierto que, en este último caso, los miembros fundadores pueden recurrir ante la jurisdicción administrativa competente (art. 17. ${ }^{\circ}$, párrafo segundo). Por su parte, esta primera autorización del ministro comporta la publicación de los datos identificativos del partido en el Boletín Oficial del Estado y la realización de su congreso constitutivo en un plazo de un año desde dicha publicación (arts. $14 .^{\circ}$ y $15 .^{\circ}$ ).

El segundo paso para alcanzar la legalización se realiza tras la celebración del congreso constitutivo del partido, durante el cual se deben adoptar los estatutos definitivos con los objetivos, la composición y la elección de sus órganos ejecutivos, las disposiciones financieras, la organización interna, etcétera (art. $\left.19 .^{\circ}\right)$; procedimiento éste que debe ser atestiguado por un notario o agente judicial (art. $\left.18 .^{\circ}\right)$. Cuentan con 15 días los

portant loi organique relative aux partis politiques” (Orden núm. 97-09 del 27 de šawāl de 1417 correspondiente al 6 de marzo de 1997 que contiene la Ley orgánica relativa a los partidos políticos), Journal Officiel de la République Algérienne, núm. 12, 6 de marzo de 1997, pp. 24-28.

${ }^{22}$ Khalfoun, "La loi sur les partis politiques", op. cit., p. 278. 
responsables del partido para depositar un nuevo expediente de solicitud de autorización ante el ministro del Interior (art. 22. ${ }^{\circ}$, párrafo primero), el cual dispone de otros 60 días para aprobar la autorización definitiva del partido o rechazarla mediante una decisión motivada (art. 22. ${ }^{\circ}$, párrafos segundo, tercero y quinto); dicha decisión puede ser igualmente recurrida ante la jurisdicción administrativa de Argel (art. 22. ${ }^{\circ}$, párrafo sexto).

Por otro lado, y siguiendo el espíritu de la reforma constitucional de 1997, la Ley Orgánica de 1997 incluye recursos legales con vistas a evitar tres cuestiones principales: la rehabilitación del FIS o el surgimiento de partidos similares, el desarrollo de partidos basados en identidades regionales y la interacción de los partidos políticos argelinos con intereses extranjeros.

En el primer caso, la norma prohíbe instrumentalizar con fines políticos los "componentes fundamentales de la identidad nacional"; entre ellos, el islam y la arabidad (art. $\left.3^{\circ}\right)$, y, en este sentido, queda excluida de la ley la posibilidad de fundar partidos sobre una base religiosa (art. 5. ${ }^{\circ}$ ).

En cuanto al segundo punto, la estrategia empleada concierne al procedimiento fundacional de los partidos, puesto que la Ley establece que el congreso constitutivo debe reunir entre 400 y 500 miembros que residan, como mínimo, en 25 wilayas diferentes, sin que el número de congresistas por wilaya pueda ser inferior a 16 (art. 18. ${ }^{\circ}$ ). Se trata, sin duda, de una medida preventiva para evitar partidos de corte regionalista, sobre todo partidos exclusivamente bereberes, especialmente activos en toda la zona de Kabilia. ${ }^{23}$ En el mismo sentido podemos citar la obligatoriedad para los miembros del partido de utilizar la lengua árabe ${ }^{24}$ para cualquier tipo de manifiesto o actividad oficial (art..$^{\circ}$ ). Aunque esto pueda suponer una continuidad respecto a la Ley de 1989, hay un agravante significativo, ya que el preámbulo de la nueva Constitución de 1996 reconocía el tamazight como uno de los componentes de la identidad nacional argelina, junto con el islam y la arabidad.

${ }^{23}$ Véase el informe realizado por Democracy Reporting International, que lleva por título Évaluation du cadre pour l'organisation des élections : Algérie, Berlín, Democracy Reporting International [2007?].

${ }^{24}$ En realidad, el artículo 4. ${ }^{\circ}$ habla de la "lengua nacional", pero la Constitución de 1996 seguía estipulando en su artículo 3. : "El árabe es la lengua nacional y oficial”. 
En lo referente a la dimensión extranjera, la norma prohíbe "todo tipo de cooperación o vínculo con cualquier partido extranjero sobre bases contrarias o antinómicas a las disposiciones de la Constitución y las leyes en vigor" (art. 7. ${ }^{\circ}$ ). En buena medida, esta normativa se relaciona con la suposición de que los partidos islamistas como el FIS, Hamas-MSP (Movimiento por la Sociedad y la Paz) y al-Nahḍa, estaban subvencionados ${ }^{25}$ por fuerzas extranjeras procedentes, sobre todo, de Arabia Saudí, las monarquías del Golfo y los Hermanos Musulmanes de Egipto. Sin embargo, esta medida puede ser también un importante hándicap para que los partidos argelinos formen parte de organizaciones internacionales en las que se inscribe su ideología, ${ }^{26}$ al tiempo que condiciona la apertura política del país, al promocionar actividades exclusivamente internas sin la posibilidad de una dimensión exterior. En todo caso, la Ley parece confinar a los partidos políticos a actividades sólo nacionales sin lazos con el exterior.

Finalmente, otra importante medida es el control económico de los partidos, que sólo pueden disponer de una única cuenta en una institución financiera nacional (art. 35. ${ }^{\circ}$ ) con fuertes sanciones penales en caso de violación de la norma. En este último caso, aunque los años de pena de cárcel (1-5 años) permanecen invariables respecto a la legislación anterior, las multas aumentan hasta los $100000 \mathrm{DA}$ (art. 38. ${ }^{\circ}$ ).

Sólo unos días después de la publicación de la Ley orgánica relativa a los partidos políticos en el Boletín Oficial del Estado (6 de marzo de 1997), el ministro del Interior, Mustapha Benmansour, exigía la obligatoriedad de ajustar sus estatutos, en un tiempo récord, a la nueva normativa con vistas a la celebración de elecciones legislativas en junio de 1997, lo cual creó un clima de gran malestar en la arena política del país. No obstante, esta Ley fue el marco jurídico en el que se creó el Reagrupamiento Nacional Democrático (RND), partido presidencialista de la administración Zéroual, que ganó ampliamente

${ }^{25}$ Véase Rafael Bustos, "El islamismo argelino: análisis de élites y recursos”, en F. Izquierdo (ed.), El islam político en el Mediterráneo. Radiografía de una evolución, Barcelona, Barcelona Centre for International Affairs, 2013, pp. 295-318.

${ }^{26}$ Khalfoun ("La loi sur les partis politiques", op. cit., p. 279) pone el ejemplo del FFS y su inclusión de la Internacional Socialista. 
unas elecciones que pretendían ${ }^{27}$ restablecer la autoridad y la legitimidad del presidente, al tiempo que consolidaban las bases institucionales del régimen. Sólo dos años después, las elecciones presidenciales del 15 de abril de 1999 daban la victoria al actual presidente Abdelaziz Buteflika, quien se presentó como candidato independiente, aunque con el apoyo del ejército y de amplios sectores sociales.

\section{Las revueltas de 2011 y sus efectos jurídicos: la Ley Orgánica de 2012 referente a los partidos políticos}

Aunque en Argelia la Primavera Árabe no tuvo ni el alcance ni las repercusiones que en otros países de la región, tampoco quedó al margen de las revueltas populares que se iniciaron a principios de enero de 2011, ni de las olas de cambio, de diferente calado, consecuencia de esta importante movilidad social. Ciertamente, las manifestaciones populares en Argelia, cuyo detonante inmediato fue el intento de subir el precio de productos básicos, no provocaron un cambio de régimen como ocurrió en Túnez, Egipto y Libia, pero las protestas por mejores condiciones de vida y la necesidad de introducir cambios políticos, institucionales y democráticos alcanzaron un nivel muy preocupante, sobre todo en la zona norte: Argel, Orán y Kabilia.

Entre los factores ${ }^{28}$ que se han esgrimido para justificar la rápida desarticulación de estas movilizaciones destacan tres: en primer lugar, las heridas, aún abiertas, derivadas de la guerra civil de los años noventa, cuya espiral de violencia provocó cerca de 150000 muertos; en segundo lugar, la debilidad y la fragmentación del tejido social, que provocaron que los levantamientos fueran puntuales y de baja intensidad; y, por último, la escasez de formaciones políticas verdaderamente independientes y críticas respecto al régimen de Buteflika, parapetado detrás del

${ }^{27}$ Véase Daho Djerbal, "Les élections législatives du 5 juin 1997 en Algérie. Enjeux politiques, logiques et acteurs”, Maghreb-Machrek, núm. 157, 1997, pp. 159-180.

${ }^{28}$ Laurence Thieux, "El papel de la sociedad civil argelina en las perspectivas de cambio político en Argelia”, Revista General de Derecho Público Comparado, núm. 11, julio de 2012, pp. 1-7. 
histórico partido FLN, que en las últimas elecciones legislativas ${ }^{29}$ del 10 de mayo de 2012 ha vuelto a rozar la mayoría absoluta (220 escaños de 462), mientras que el resto se repartió entre 26 partidos y con la particularidad de que el segundo partido más votado (RND) obtuvo solamente 68 escaños, lo que evoca los viejos tiempos de preponderancia del FLN.

Sin embargo, los disturbios sociales sí que provocaron una rápida respuesta del régimen, que, como medida de contención, anunció enseguida acciones socioeconómicas y concesiones políticas que "se inscriben en una lógica de reformas top down estrechamente controladas" ${ }^{30}$ De este modo, no sólo se descartó la subida en los precios de los productos de primera necesidad, sino que, aprovechando cierta bonanza económica ${ }^{31}$ derivada de la explotación de los hidrocarburos, bajaron los precios y se aumentó el salario de los funcionarios y las pensiones de los jubilados. Las movilizaciones también se reflejaron en ciertas iniciativas políticas, como el levantamiento del Estado de emergencia, vigente desde 1992; el adelanto de las elecciones legislativas a mayo de 2012; la dinamización del debate en torno a la reforma constitucional y la promulgación de leyes relacionadas con las libertades públicas, que pretenden simbolizar el "nuevo talante aperturista" del régimen. Entre éstas destacan tres, aprobadas el 12 de enero de 2012: la Ley orgánica 05-12 relativa a la información, la Ley 06-12 relativa a las asociaciones, y, por último, la Ley orgánica 04-12 relativa a los partidos políticos, ${ }^{32}$ que forma parte de mi objeto de estudio y de la que hablaré a continuación.

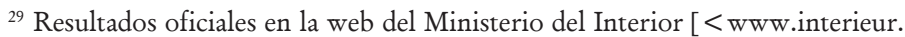
gov.dz/PublishingFiles/SyntheseResultats_Fr.pdf >, consultado el 21 de noviembre de 2015].

${ }^{30}$ Louisa Driss-Aït Hamadouche, L'Algérie face au printemps arabe: pressions diffuses et résilience entretenue, Barcelona, Instituto Europeo del Mediterráneo, 2012.

${ }^{31}$ Carlos Echeverría, Argelia a los dos años de los conatos de revueltas: situación política y de seguridad, Documento de Opinión 31/2013, Madrid, Instituto Español de Estudios Estratégicos, abril de 2013.

32 Texto completo de la Ley orgánica en: República Argelina, "Qānūn 'uḍ̄ī raqm 12-04 mu'arraj fì 18 șafar 'ām 1433 al-muwāfiq 12 yanā’yir sana 2012 yata'allaq bi-l-ahazāb al-siyāsiyya" (Ley orgánica número 12-04 del 18 de șafar de 1433, correspondiente al 12 de enero de 2012, relativa a los partidos políticos), Al-ŶYarida al-Rasmiyya

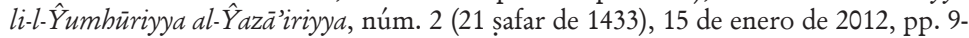
18. Versión francesa en: République Algérienne, "Loi organique n 12-04 du 18 safar 


\section{Objetivos, fundamentos y principios de los partidos políticos}

Una de las primeras preocupaciones que parece mostrar la Ley de partidos de 2012 es establecer medidas legales que imposibiliten el resurgimiento de antiguas formaciones como el FIS, o que organizaciones radicales y violentas, como el Grupo Islámico Armado (GIA), lleguen a alcanzar un estatus legal, enmascaradas tras alguna sigla política. Igualmente, la norma pretende evitar la rehabilitación, en cualquier forma, de históricos líderes islamistas como Abbasi al-Madani o 'Ali Belhadj, sobre todo teniendo en cuenta el éxito que han alcanzado en Túnez y Egipto otros dirigentes y partidos de tendencia similar. De esta manera, prácticamente desde el inicio de la Ley, el artículo $5 .^{\circ}$ prohíbe crear un partido político "a toda persona responsable de instrumentalizar la religión que condujo a la tragedia nacional", así como "a cualquier participante en acciones terroristas que se niegue a reconocer su responsabilidad en la concepción, programación y ejecución de una política que incite a la violencia", haciendo de nuevo una clara alusión a los antiguos dirigentes del Fis que nunca han reconocido responsabilidad alguna en la denominada "tragedia nacional". ${ }^{33}$ Otros artículos van en el mismo sentido, como el $6 .^{\circ}$, que prohíbe utilizar el nombre o las siglas de partidos contrarios a los "intereses de la nación y a los ideales de la Revolución de 1954", o el artículo $9 .^{\circ}$, que, además del uso de la violencia, prohíbe "inspirarse en el programa de acción de un partido político judicialmente disuelto".

Pero la Ley de partidos de 2012 incluye también una casuística que puede convertirse en un eficaz instrumento al servicio del poder para prohibir la creación o permanencia de formaciones críticas al sistema, y cuya principal característica es su alto grado de imprecisión y ambigüedad. De esta manera,

1433 correspondant au 12 janvier 2012 relative aux partis politiques” (Ley orgánica núm. 12-04 del 18 de șafar de 1433, correspondiente al 12 de enero de 2012, relativa a los partidos políticos), Journal Officiel de la République Algérienne, núm. 2, 15 de enero de 2012, pp. 9-15.

${ }^{33}$ Véase Zahir Oumahdhi, "Loi régissant la vie politique. L'Algérie s'offre de nouvelles règles de fonctionnement”, Dzeriet, diciembre de 2011. Véase igualmente Slate Afrique, "L'islamiste algérien Madani conteste une loi interdisant son parti", 6 de diciembre de 2011. 
el artículo $8 .^{\circ}$ prohíbe constituir partidos políticos contrarios a "los valores y componentes fundamentales de la identidad nacional", "los valores de la Revolución del 1 de noviembre de 1954", "la moral islámica", "la unidad y la soberanía nacional", "las libertades fundamentales", "la independencia del país y la soberanía del pueblo", "el carácter democrático y republicano del Estado" y "la seguridad y la integridad del territorio nacional", es decir, criterios extremadamente vagos e indeterminados que pueden estar sujetos a interpretaciones arbitrarias de la administración..$^{34}$

\section{Creación de partidos políticos}

En lo concerniente a la creación de partidos políticos, la actual Ley de 2012 parece descartar definitivamente el carácter declarativo que inspiraba a la primera norma de 1989 y se inclina por un procedimiento más complejo que se asemeja al estipulado en la Ley de 1997. De esta forma, establece de nuevo dos fases para constituir un partido político, con la particularidad de que cada una de ellas se encuentra sometida a la autorización expresa del ministro del Interior.

Al igual que en la ley precedente, el proceso comienza con el depósito de un expediente ante el Ministerio del Interior a cambio de un resguardo (art. 18. ${ }^{\circ}$ ) que acredita esta formalidad. Dicho expediente debe incluir (art. 19..$^{\circ}$ ): una solicitud de constitución firmada por al menos tres miembros fundadores, tres ejemplares de los estatutos provisionales, el anteproyecto del programa político y diversos documentos relacionados con la identificación y la situación legal de los fundadores. Sin embargo, se incluye una novedad que no aparecía en la norma precedente, ${ }^{35}$ pero que tiene el mismo objetivo: evitar el surgimiento de formaciones regionalistas e identitarias, principal-

${ }^{34}$ Réseau Euro-Méditerranéen des Droits de l'Homme, Réformes politiques ou verrouillage supplémentaire de la société civile du champ politique? Une analyse critique, Copenhague, Réseau Euro-Méditerranéen des Droits de l'Homme, 2012, pp. 45-46.

${ }^{35}$ La Ley orgánica de 1997, en su artículo 14.3 exigía "un compromiso escrito y firmado por, al menos, 25 miembros fundadores residentes en un tercio $(1 / 3)$ del número de wilayas del país", pero no exigía la firma de dos miembros fundadores por wilaya. 
mente partidos berberistas. De este modo, el expediente debe incluir también "un compromiso escrito y firmado por, al menos, dos miembros fundadores por wilaya, procedentes, al menos, de la cuarta parte de las wilayas del territorio nacional". Si tenemos en cuenta que Argelia está formada por 48 wilayas, esto significaría que, como mínimo, deben estar implicadas 12 provincias diferentes y 24 miembros fundadores (dos por wilaya) en la creación de cualquier partido, lo cual puede suponer una importante desventaja para la creación de partidos.

Una vez depositado el expediente, se inicia el primer proceso de autorización por parte del ministro del Interior, el cual dispone, al igual que en la normativa anterior, de 60 días para aprobar o denegar la solicitud (art. 20. ${ }^{\circ}$ ). En este último caso, los miembros fundadores podrán recurrir al Consejo de Estado $^{36}$ en un plazo máximo de 30 días desde la fecha de notificación (art. $21 .^{\circ}$ y art. $22 .^{\circ}$ ). Por otra parte, esta autorización del ministro del Interior conlleva, en primer lugar, la publicación de los principales datos del partido (nombre, sede, miembros fundadores, firmantes del compromiso) en dos periódicos nacionales ${ }^{37} \mathrm{y}$, en segundo término, la realización de un congreso constituyente en un plazo máximo de un año, igual que en la Ley precedente, aunque actualmente se articula la posibilidad de solicitar al ministro del Interior una prórroga máxima de seis meses (art. 26. ${ }^{\circ}$ ).

La segunda fase del proceso de constitución del partido se inicia con la celebración de un congreso constituyente, atestiguado por un agente judicial (art. 25. ${ }^{\circ}$ ), durante el cual se han de aprobar, entre otras cuestiones, los estatutos, el programa político y el reglamento interno definitivos. De nuevo, el capítulo dedicado a su autorización comienza con los requisitos necesarios para que este órgano sea representativo del mayor número de wilayas posibles del país, con lo que se evita la cons-

${ }^{36}$ En la Ley orgánica de 1997, el recurso debía formularse ante la jurisdicción administrativa competente (art. 17. ${ }^{\circ}$ ). El Consejo de Estado fue creado en 1996 como órgano regulador de la actividad de las jurisdicciones administrativas. Entre sus funciones, destaca la gestión de los litigios que se producen entre los individuos, los partidos políticos, las asociaciones y el Estado. El presidente de este Consejo es elegido por el presidente de la República (art. 78.4 de la Constitución).

${ }^{37}$ En la Ley de 1997, los datos identificativos del partido debían publicarse en el Boletín Oficial del Estado (art. 15. ${ }^{\circ}$ ). 
titución de partidos regionalistas o culturalistas ya comentados. Según el artículo 24. ${ }^{\circ}$, "para que la celebración del congreso constituyente sea válida, deberá ser representada por, al menos, un tercio (1/3) del número de las wilayas repartidas a lo largo del territorio nacional". De forma similar a la Ley de 1997, ${ }^{38}$ el número de congresistas no puede ser inferior a 16 por cada wilaya ni el de afiliados, inferior a 100 por cada wilaya. Como novedad significativa, este mismo artículo $24 .^{\circ}$ señala que el congreso debe reunir una proporción representativa de mujeres, aunque no menciona porcentajes como en los casos anteriores, posiblemente porque el interés del régimen por la igualdad de género es menor.

Durante la celebración del congreso se debe elegir a un miembro "para que deposite, a lo largo de los 30 días $^{39}$ siguientes, un expediente de solicitud de aprobación ante el ministro encargado del Interior, a cambio de la entrega inmediata de un recibo de depósito" (art. 27. ${ }^{\circ}$ ). Con este nuevo depósito se inicia el segundo proceso de autorización por parte del ministro del Interior, que dispone de 60 días (art. 29. ${ }^{\circ}$ ) para conceder la aprobación definitiva de constitución del partido o denegarla mediante una justificación legal (art. 30. ${ }^{\circ}$ ). En este último supuesto, la decisión puede ser recurrida ante el Consejo de Estado, ${ }^{40}$ en un plazo máximo de dos meses (art. 33. ${ }^{\circ}$ ). La segunda aprobación del Ministerio comporta la publicación en el Boletín Oficial de la República Argelina, momento a partir del cual el partido adquiere personalidad y capacidad jurídica (art. 32. $\left.{ }^{\circ}\right)$.

La aprobación del partido político no es la única potestad que tiene el ministro del Interior. Su poder de decisión vuelve a surgir en el caso de que el partido decida, en un momento determinado, introducir cualquier tipo de cambio en su organización, composición de miembros directivos o en sus estatutos,

${ }^{38}$ La principal diferencia entre la Ley de 1997 y la de 2012 reside en que, en el primer caso, los congresistas deben ser elegidos por, al menos, 2500 afiliados ( $\operatorname{art} .18 .^{\circ}$ ), mientras que en la norma actual los congresistas deben ser elegidos por, al menos, 1600 afiliados $\left(\operatorname{art} .24 .^{\circ}\right)$.

${ }^{39}$ En la Ley de 1997 el plazo era de 15 días (art. 22. ${ }^{\circ}$ ).

${ }^{40}$ En la Ley de 1997, el órgano de recurso era la jurisdicción administrativa de Argel (art. 22. ${ }^{\circ}$ ). 
en cuyo caso debe notificarlo al ministro en un plazo máximo de 30 días, y éste dispondrá, a su vez, de un mes para comunicar su decisión (art. 36. ${ }^{\circ}$ ). Resultan significativas las diferencias respecto a la legislación anterior de 1997 (art. 20. ${ }^{\circ}$ ), donde también aparecía esta disposición, pero en aquel caso sólo se exigía una declaración al ministro del Interior y no una aprobación expresa de su parte. Como afirma la Red Euromediterránea de Derechos Humanos, "las disposiciones del artículo $36 .^{\circ}$ fortalecen la voluntad de control de la administración sobre los partidos políticos, no sólo en el momento de su creación, sino también en su organización: se trata de una injerencia grave en la organización interna de los partidos políticos". ${ }^{41}$

\section{Organización y funcionamiento de los partidos políticos}

Los artículos dedicados a la organización y el funcionamiento de los partidos políticos (Título tercero de la Ley de 2012, arts. $\left.38 .^{\circ}-51 .^{\circ}\right)$ tienen, en general, un carácter teorizante, lo que los convierte en una especie de declaración de intenciones. De este modo, el artículo $38 .^{\circ}$ obliga a los partidos a funcionar sobre "bases democráticas cimentadas en las reglas de la libre elección de sus afiliados", y por el artículo 39. "los estatutos determinarán las competencias y modalidades de organización y funcionamiento de los órganos del partido político, según los principios democráticos”. Algo similar pasaría con el artículo $41 .^{\circ}$, en el que se afirma que "todo partido político deberá incluir un porcentaje de mujeres dentro de sus órganos directivos", aunque no se especifica porcentaje ni procedimiento alguno.

Igualmente, ciertos artículos vuelven a incidir en temas ya tratados, como el $40 .^{\circ}$, que obliga a los partidos a establecer estructuras centrales permanentes y estructuras locales en, al menos, la mitad del número de wilayas del país, y que especifica además que "estas estructuras deberán expresar, mediante su presencia, el carácter nacional del partido político”. De nuevo

${ }^{41}$ Réseau Euro-Méditerranéen des Droits de l'Homme, Réformes politiques..., op. cit., pp. 47-48. 
estamos ante una medida cuya finalidad es evitar el surgimiento de partidos localistas, regionalistas o identitarios. Tampoco sorprende que en la sección sobre el funcionamiento de los partidos reaparezca la omnipresente figura del ministro del Interior, al cual se le debe notificar la composición de los órganos locales del partido, así como cualquier cambio que ocurra en un plazo de un mes (art. $\left.44 .^{\circ}\right)$.

El componente lingüístico es otro aspecto que aparece en la sección dedicada a la actividad de los partidos políticos. Si, como ya se dijo, la Ley de 1997 exigía a los partidos utilizar la lengua árabe (lengua nacional), la actual Ley de 2012, en su artículo 48, les prohíbe "utilizar lenguas extranjeras en todas sus actividades”. En la práctica, la ley permite el uso del árabe y del tamazight, reconocido como lengua nacional en la reforma constitucional de 2002, pero prohíbe un idioma que, por motivos históricos, se encuentra aún muy anclado en la sociedad argelina: el francés, lo cual no deja de ser un impedimento para ciertos partidos cuyo canal de comunicación suele ser este idioma y una contradicción respecto a la propia realidad de la administración argelina, que sigue usando el francés en muchos dominios de la vida política, social y cultural.

Finalmente, la tercera sección del título dedicado a la organización y el funcionamiento de los partidos políticos trata sobre las relaciones de éstos con otras formaciones. Lo más significativo es que, aunque la Ley permite mantener relaciones con partidos extranjeros (art. 51. ${ }^{\circ}$ ), prohíbe "llevar a cabo acciones en el extranjero con el objetivo de perjudicar al Estado, sus símbolos, sus instituciones y sus intereses económicos y diplomáticos”. En realidad, esta norma puede erigirse en un eficaz instrumento contra la libertad de expresión, puesto que cualquier manifestación que los líderes políticos hagan en el extranjero contra las políticas oficiales del Estado podrían ser interpretadas por la administración como un atentado a los símbolos y las instituciones del Estado, o a sus intereses económicos y diplomáticos. 


\section{Recursos económicos de los partidos políticos}

Todo el Título cuarto de la Ley de 2012, compuesto por 12 artículos (arts. 52. ${ }^{\circ}-63 .^{\circ}$ ), está dedicado a regular las finanzas. Si bien las actividades del partido pueden estar financiadas por diferentes medios (cuotas de sus miembros, donaciones, legados, ganancias derivadas de sus actividades y posibles ayudas del Estado) (art. 52..$^{\circ}$, no obstante, queda prohibido "recibir, directa o indirectamente, apoyo financiero o material de cualquier lugar extranjero, en cualquier título o forma" (art. 56. ${ }^{\circ}$ ). Esta norma tiene un objetivo similar al estipulado en la Ley de 1997: ${ }^{42}$ evitar que partidos de corte islamista, legalizados o no, reciban estímulo económico de países ${ }^{43}$ como Arabia Saudí o de movimientos de gran pujanza como los Hermanos $\mathrm{Mu}$ sulmanes de Egipto.

También los recursos legales están sujetos a diversas normas y procedimientos de control: se establece que las donaciones, los legados y los donativos deberán proceder de personas físicas identificadas, y para ello se establece una cantidad anual máxima $^{44}$ (art. 55. ${ }^{\circ}$ ); se prohíbe el ejercicio de actividades comerciales (art. 57..$^{\circ}$ ); se establecen mecanismos de control para las subvenciones públicas (art. 58. ${ }^{\circ}$ ), de las cuales se benefician, sobre todo, los partidos mayoritarios, ${ }^{45}$ y se obliga al responsable del partido a presentar ante los delegados del partido o los congresistas un informe financiero acreditado por un experto contable (art. $60 .^{\circ}$ ).

En cuanto al control de la gestión económica del partido, la Ley de 2012 establece dos mecanismos: en primer lugar, una contabilidad por partida doble y un inventario de sus bienes muebles e inmuebles, con la obligación de presentar las cuentas anuales ante la administración competente (art. $\left.61 .^{\circ}\right)$; y, en segundo lugar, una cuenta abierta en un banco nacional o en

42 Artículo 7. de la Ley de 1997: "Está prohibido cualquier tipo de cooperación o vínculo con cualquier partido extranjero sobre bases contrarias o antinómicas a las disposiciones de la Constitución y las leyes en vigor".

${ }^{43}$ Véase Bustos, "El islamismo argelino", op. cit., pp. 295-318.

${ }^{44}$ La cantidad máxima estipulada es 300 veces el salario nacional mínimo garantizado, por donación y año (art. 55..$^{\circ}$ ).

${ }^{45}$ Las subvenciones del Estado se conceden "según el número de escaños obtenidos en el parlamento y el número de sus electos en las asambleas” (art. 58. ${ }^{\circ}$ ). 
una de sus sucursales (art. 62. ${ }^{\circ}$ ), donde se deben abonar todos los recursos económicos del partido, incluidos donaciones, legados, etcétera (arts. $53 .^{\circ}$ y $55 .^{\circ}$ ).

\section{Suspensión y disolución de los partidos políticos}

De nuevo en el apartado dedicado a la suspensión y la disolución (Título quinto, arts. $64 .^{\circ}-76 .^{\circ}$ ) reaparece la omnipresente figura del ministro del Interior, con un protagonismo determinante tanto en el caso de partidos en proceso de aprobación como en el de los ya autorizados legalmente. En el primer caso, es competencia exclusiva del ministro suspender las actividades de los fundadores del partido y ordenar el cierre de sus locales no solamente cuando considere que se violan las disposiciones de las leyes en vigor, sino también "en casos de urgencia y perturbaciones inminentes del orden público" (art. 64. ${ }^{\circ}$ ). Lo único que alega la norma es que la decisión debe ser razonada y comunicada a los miembros fundadores, los cuales podrán recurrir ante el Consejo de Estado (art. 64. ${ }^{\circ}$ ). En el segundo supuesto, es decir, cuando un partido autorizado cometa alguna infracción, la instancia que tiene la potestad para suspenderlo o cerrar temporalmente sus sedes es el Consejo de Estado (art. 66. ${ }^{\circ}$ ), pero, se añade en el siguiente artículo, "legalmente informado por el ministro encargado del Interior", el cual debe advertir al partido de la necesidad de ajustarse a las disposiciones legales en un plazo determinado (art. 67..$^{\circ}$ ).

El protagonismo del ministro del Interior es determinante a la hora de ordenar la disolución definitiva de un partido político, puesto que es el encargado de solicitarlo ante el Consejo de Estado (art. 69. ${ }^{\circ}$ ), que es la instancia que ejecuta la petición ministerial. Además de cuestiones como la infracción de las disposiciones de la ley o el ejercicio de actividades distintas a las estipuladas en sus estatutos, lo más significativo de este apartado es que un partido político podría ser disuelto si no presenta candidatos a cuatro elecciones legislativas y locales consecutivas (art. $70^{\circ}$ ), lo cual podría suponer un considerable riesgo para algunos partidos de oposición que, como medida de lucha o de protesta, opten reiteradamente por el boicot a las eleccio- 
nes o promuevan la abstención durante sus campañas electorales. Como sostiene la Red Euromediterránea de Derechos Humanos, esta norma interfiere en la toma de decisiones de los partidos políticos y supone una nueva injerencia del poder en sus asuntos internos. ${ }^{46}$

En la misma línea, el artículo 71 establece que "en caso de urgencia y antes de la sentencia de la causa judicial interpuesta, el ministro encargado del Interior podrá adoptar todas las medidas cautelares necesarias para evitar, afrontar o poner fin a las situaciones de urgencia y violación de las leyes en vigor". Es decir, de nuevo la Ley utiliza un término excesivamente vago e indeterminado, sujeto a la apreciación personal (caso de urgencia), con el fin de permitir al ministro la posibilidad de actuar ante una amplia casuística antes de la obtención de una sentencia judicial definitiva, porque, incluso la interposición de un recurso por parte del partido afectado no impide la aplicación de la decisión del ministro (art. $710^{\circ}$ ).

\section{Sanciones penales}

Aunque la Ley de 1997 contenía varios artículos sobre penas y multas en caso de infracción de la ley, estos aspectos estaban incluidos en el apartado dedicado a las disposiciones financieras. No ocurre lo mismo en la Ley de 2012, que introduce un título específico (Título sexto, arts. $77 .{ }^{\circ}-81 .^{\circ}$ ), aunque breve, bajo la denominación de "Disposiciones penales", del que se desprende el interés por darle una mayor visibilidad a estas cuestiones.

El avance más significativo de la legislación actual reside en que se ha eliminado la pena de cárcel para los miembros, fundadores o dirigentes de partidos que infrinjan la ley, como ocurría en la anterior norma. ${ }^{47}$ Sin embargo, la Ley de 2012

\footnotetext{
${ }^{46}$ Réseau Euro-Méditerranéen des Droits de l'Homme, Réformes politiques..., op. cit., p. 48.

47 El artículo $38 .^{\circ}$ de la Ley de 1997 contemplaba una pena de cárcel de entre uno y cinco años para "cualquier persona que, infringiendo las disposiciones de la presente Ley, funde, dirija o administre un partido político, bajo la forma o denominación que sea”.
} 
ha aumentado considerablemente las multas, que ascienden a un mínimo de 300000 DA (anteriormente 5000) y un máximo de 600000 DA (antes 100000$) ;{ }^{48}$ cantidades aplicables por igual a quien "dirija, administre o forme parte de un partido político que continúe con sus actividades o vuelva a constituirse durante su periodo de suspensión o tras su disolución” (art. 78. ${ }^{\circ}$ ).

\section{Conclusión}

Tal y como se planteó en la hipótesis, podemos afirmar que desde la adopción de la primera Ley de partidos políticos en 1989, la más liberal que ha conocido el país, la legislación ha experimentado una tendencia represiva. Como consecuencia, las posteriores legislaciones $(1997,2012)$ han puesto en marcha complejos mecanismos de control a favor de las instituciones gubernamentales con una doble finalidad: en primer lugar, controlar estrechamente la creación y las actividades de los partidos políticos, sobre todo los más críticos hacia el régimen o el sistema; en segundo lugar, garantizar a la administración, a través del ministro del Interior, la posibilidad de interferir o neutralizar sus actividades, miembros o sedes, por la simple vía administrativa, alegando cualesquiera de los múltiples motivos ambiguos que contemplaba dicha norma.

En cuanto a la actual Ley Orgánica de 2012, se caracteriza por vehicular el espíritu de control que impregnaba la legislación de 1997, pero con la particularidad de que, en muchas ocasiones, introduce mecanismos aún más estrictos y elaborados que en aquélla, como

- El establecimiento de dos fases diferentes para legalizar un partido político, sometidas al beneplácito del ministro del Interior, quien también controla cualquier tipo de cambio en su organización o composición.

- La introducción de una gran cantidad de criterios vagos, indeterminados y ambiguos, relacionados con el islam, la patria o el Estado, que pueden provocar la suspensión o la

${ }^{48}$ Las cifras entre paréntesis corresponden a la Ley de 1997, art. 38. ${ }^{\circ}$. 
disolución de un partido político o sus actividades por parte del ministro del Interior o el Consejo de Estado.

- La imposibilidad de rehabilitar o desarrollar partidos políticos que en el pasado hayan tenido un importante éxito social, como es el caso del FIS.

- La implantación de un complejo sistema de representatividad de la mayoría de las wilayas del país, para evitar el surgimiento de partidos de corte regionalista o identitarios.

- La prohibición de idiomas extranjeros en las actividades del partido, lo que constriñe la libertad de algunos sectores sociales francófonos.

- La coerción de la libertad de expresión como consecuencia de criticar o valorar en el extranjero las políticas oficiales, puesto que podría ser considerado como un perjuicio al Estado, sus símbolos o instituciones.

- La prohibición de recibir apoyo financiero del extranjero y la puesta en marcha de diferentes mecanismos de control de la economía y el patrimonio del partido.

- Las amplias prerrogativas del ministro del Interior para suspender o disolver los partidos durante el proceso de creación o una vez autorizados legalmente. ${ }^{49}$

Dirección institucional del autor:

Departamento de Estudios Semíticos

Universidad de Granada

Campus Universitario de Cartuja

18071, Granada, España

\section{Bibliografía}

ADDI, Lahouari, "L'armée, la nation et l'État en Algérie", Confluences Méditerranée, núm. 29, 1999, pp. 39-46.

ADDI, Lahouari, "Les partis politiques en Algérie”, Revue des Mondes

${ }^{49}$ Este trabajo se enmarca dentro del proyecto de investigación "Ideología, texto y discurso: las narrativas del cambio social en el Norte de África” (FFI 2016-76307-R), subvencionado por la Dirección General de Investigación Científica y Técnica (España). Investigador principal: Juan Antonio Macías Amoretti 
Musulmans et de la Méditerranée, núms. 111-112, 2006, pp. 139162.

Aghrout, Ahmed, "Reformas políticas en Argelia. ¿Cambios verdaderos o meros ajustes?”, en Y. H. Zoubir y H. Amirah (coords.), El Magreb. Realidades nacionales y dinámicas regionales, Madrid, Síntesis, 2008, pp. 63-86.

Aїт KAKI, Maxime, De la question berbère au dilemme kabyle à l'aube du XXI siècle, París, L'Harmattan, 2004.

BeKE, Dirk, "La Constitution algérienne de 1989 : une passerelle entre le socialiste et l'islamisme?", Afrika Focus, año 7, núm. 3, 1991, pp. 241-272.

Bendourou, Omar, "La nouvelle Constitution algérienne du 28 février 1989”, Revue de Droit Publique, núm. 5, 1989, pp. 1305-1328.

Bustos, Rafael, "El islamismo argelino: análisis de élites y recursos”, en F. Izquierdo (ed.), El islam político en el Mediterráneo. Radiografía de una evolución, Barcelona, Barcelona Centre for International Affairs, 2013, pp. 295-318.

Bustos, Rafael, "Elecciones y cambio político en Argelia”, en María Angustias Parejo (ed.), Entre el autoritarismo y la democracia. Los procesos electorales en el Magreb, Barcelona, Bellaterra, 2010, pp. 149-184.

Bustos, Rafael, "Estudio sobre la poliarquía en Argelia: lógicas de participación y competición en las elecciones argelinas", en I. Álvarez-Ossorio y L. Zaccara (eds.), Elecciones sin elección. Los procesos electorales en Oriente Medio y el Magreb, Madrid, Ediciones del Oriente y el Mediterráneo, 2009, pp. 326-347.

Chaker, Salem, "Quelques évidences sur la question berbère”, Confluences, núm. 11, 1994, pp. 105-114.

Democracy Reporting International, Évaluation du cadre pour l'organisation des élections: Algérie, Berlín, Democracy Reporting International [2007?]. [ < democracy-reporting.org/newdri/wpcontent/uploads/2016/02/report_algeria_f.pdf $>$, consultado en octubre de 2016].

DJAZIRI, Moncef, "La problématique partisane dans les systèmes politiques du Maghreb. Relance des études comparatives”, Annuaire de l'Afrique du Nord, núm. 34, 1995, pp. 423-449.

Djerbal, Daho, "Les élections législatives du 5 juin 1997 en Algérie. Enjeux politiques, logiques et acteurs", Maghreb-Machrek, núm. 157, 1997, pp. 159-180.

Driss-AÏ̈T HAMADOUCHE, Louisa, "L’Algérie face au printemps arabe: pressions diffuses et résilience entretenue", en Annuaire de la Mediterranée, Barcelona, Instituto Europeo del Mediterráneo, 
2012, pp. 178-183. [<www.iemed.org/observatori-fr/areesdanalisi/arxius-adjunts/anuari/med.2012/hamadouche fr.pdf/ view?set language $=\mathrm{fr}>$, consultado el 21 de noviembre de 2015.] Echeverría, Carlos, Argelia a los dos años de los conatos de revueltas: situación política y de seguridad, Documento de Opinión 31/2013, Madrid, Instituto Español de Estudios Estratégicos, abril de 2013. [<www.ieee.es/Galerias/fichero/docs opinion/2013/ DIEEEO31-2013_Argelia_SituacionPoliticaSeguridad_CarlosEcheverria.pdf $>$, consultad̄o el 21 de noviembre de 2015.]

Khalfoun, Tahar, "La loi sur les partis politiques : un pluralisme administré”, en G. Meynier (ed.), L’Algérie contemporaine. Bilan et solutions pour sortir de la crise, París-Montreal, L'Harmattan, 2000, pp. 272-273.

MaÑÉ Estrada, Aurelia, "Ajuste estructural en Argelia. Un diagnóstico equivocado para una difícil reforma”, Nación Árabe, núm. 36, 1998, pp. 115-127.

Martín MuÑoz, Gema, "La nueva Constitución argelina: hacia la III República”, Revista de Estudios Políticos, núm. 67, 1990, pp. 261296.

Meneses, Rosa, "La exclusión del islam político en Argelia. Implicaciones y consecuencias de la inacabada construcción del Estado", Afers Internacionals, núms. 93-94, 2011, pp. 73-88.

MonTABES, Juan, Las otras elecciones. Los procesos y sistemas electorales en el Magreb, Madrid, Agencia Española de Cooperación Internacional, 1999.

OUMAHDHI, Zahir, “Loi régissant la vie politique. L'Algérie s'offre de nouvelles règles de fonctionnement", Dzeriet, diciembre de 2011. [<www.dziri-dz.com/?p $=536>$, consultado el 27 de noviembre de 2015].

Pérez Beltrán, Carmelo, "Democracia, sociedad civil y derechos humanos en el Magreb”, Nova África, núm. 12, 2003, pp. 85-105. República Argelina, “Amr raqm 97-09 mu'arraj fī 27 šawāl 'ām 1417 al-muwāfiq 6 mārs sana 1997 yatadamman al-qānūn al-'uḍīi almuta'allaq bi-l-ahzāb al-siyāsiyya”, Al-ŶYarīla al-Rasmiyya li-l$\hat{Y}$ umbūriyya al- $\hat{Y}$ azä'iriyya, núm. 12 (27 šawāl de 1417), 6 de marzo de 1997, pp. 30-35.

República Argelina, "Qānūn raqm 89-11 al-mu'arraj fī 2 dī l-hîŷya 'ām 1409 al-muwāfiq 5 yūlīw sana 1989 yata'allaq bi-l-yam iyyāt dāt țābi“ siyāsī”, Al-Ŷarida al-Rasmiyya li-l-Ŷumbūriyya al$\hat{Y}$ azá’iriyya, núm. 27, 5 de julio de 1989, pp. 714-718.

República Argelina, "Qānūn 'uḍ̂̄ī raqm 12-04 mu'arraj fī 18 ṣafar 'ām 1433 al-muwāfiq 12 yanā'yir sana 2012 yata'allaq bi-l-aḥzāb al- 


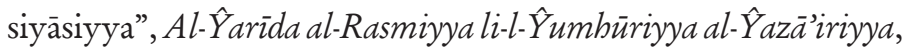
núm. 2 (21 șafar de 1433), 15 de enero de 2012, pp. 9-18.

République Algérienne, "Loi no 89-11 du 5 juillet 1989 relative aux associations à caractère politique", Journal Officiel de la République Algérienne, núm. 27, 5 de julio de 1989, pp. 604-607.

République Algérienne, "Loi organique n 12-04 du 18 safar 1433 correspondant au 12 janvier 2012 relative aux partis politiques", Journal Officiel de la République Algérienne, núm. 2, 15 de enero de 2012, pp. 9-15.

République Algérienne, "Ordonnace no 97-09 du 27 chaoual 1417 correspondant au 6 mars 1997 portant loi organique relative aux partis politiques", Journal Officiel de la République Algérienne, núm. 12, 6 de marzo de 1997, pp. 24-28.

Réseau Euro-Méditerranéen des Droits de l'Homme, Réformes politiques ou verrouillage supplémentaire de la société civile du champ politique? Une analyse critique, Copenhague, Réseau EuroMéditerranéen des Droits de l'Homme, 2012.

Slate Afrique, "L'islamiste algérien Madani conteste une loi interdisant son parti", 6 de diciembre de 2011. [ < slateafrique.com/77809/ lislamiste-algerien-madani-conteste-une-loi-interdisant-sonparti $>$, consultado el 28 de noviembre de 2015.]

ThIEUx, Laurance, "El papel de la sociedad civil argelina en las perspectivas de cambio político en Argelia", Revista General de Derecho Público Comparado, núm. 11, julio de 2012, pp. 1-7. THIEUX, Laurance, Islamismo y democracia en Argelia. Francia y Estados Unidos frente al conflicto, Madrid, Ediciones del Oriente y del Mediterráneo, 2008. 